\title{
Association Between Chlamydia pneumoniae infection and Lung Cancer: A Meta-Analysis
}

\section{Chunxi Wang}

Tianjin Third Central Hospital

Naxin Zhang ( $\sim$ zhangnaxin801@163.com )

Tianjin Third Central Hospital https://orcid.org/0000-0002-2878-2433

\section{Liang Gao}

Tianjin Third Central Hospital

\section{Research article}

Keywords: Chlamydia pneumoniae infection, lung cancer, meta-analysis, risk factors

Posted Date: September 13th, 2019

DOl: https://doi.org/10.21203/rs.2.14400/v1

License: (c) (i) This work is licensed under a Creative Commons Attribution 4.0 International License. Read Full License

Version of Record: A version of this preprint was published at Translational Cancer Research on December 1st, 2019. See the published version at https://doi.org/10.21037/tcr.2019.10.35. 


\section{Abstract}

Aims: To explore the correlation between Chlamydia pneumoniae infection and lung carcinoma. Methods: Databases of PubMed, Embase, Embase, Ovid, Wanfang and China National Knowledge Infrastructure (CNKI) database were investigated for eligible literatures from their establishments to February, 2019. Included studies were selected according to specific eligibility criteria. Statistical analysis were performed by RevMan 5.3 software. Results: Thirteen studies with 2553 lung carcinoma cases and 2460 controls were eligible for metaanalysis. The pooled results indicated that the $\mathrm{C}$. pneumoniae infection IgA significant increased the risk of lung carcinoma (OR=3.19; $95 \% \mathrm{Cl}=1.96-5.19 ; \mathrm{p}<0.00001)$ by random effect model. And for serum IgG, the pooled OR was 2.02 ( $95 \% \mathrm{Cl}=1.29-3.16 ; \mathrm{p}<0.00001)$ by using the random effects model. The results indicated that the $\lg \mathrm{A}$ positive rate was significantly higher in lung cancer patients than healthy controls. Conclusions: This metaanalysis revealed that $\mathrm{C}$. pneumoniae infection may be a potential risk factor for lung carcinoma. However, due to its significant heterogeneity in the included studies, the consequence should be understand with caution.

\section{Introduction}

Lung cancer is the most common diagnosed cancer, accounting for $11.6 \%(2,093,876$ new cases) of new carcinomatosis cases and 18.4\% (1,761,007 deaths) of all cancer deaths in 2018[1]. The 1-year and 5-year survival rates were $42 \%$ and $15 \%$, respectively, and it is poor while compared with those in high incidence of other cancer[2]. The mechanism of lung cancer has not been fully understood. Smoking status was identified as the most crucial independent risk element for lung cancer [3,4]. Some literatures also proved that both genetic and environment factors were related to the risk of lung carcinoma, such as exposure to radon and asbestos, air pollution, second-hand smoking and chronic bacterial infection and parasitic infections (Chlamydia pneumoniae)[5,6].

Chlamydia pneumoniae (C. pneumoniae), a gram-negative bacterium, has been present as an individual species since 1989, is a common respiratory pathogen that causes the chronic and persistent respiratory infections $[7,8]$. C. pneumoniae infection not only lead to worldwide widespread respiratory infections such as pneumonia, pharyngitis, bronchitis, and sinusitis, but also associated with asthma, chronic obstructive pulmonary disease, and atherosclerosis[9]. Kuo et al have reported that $C$. pneumoniaeis infection causes an average of 7-10\% of community-acquired pneumonia (CAP) and $5 \%$ of bronchitis and sinusitis cases among adults[10]. Laurila et al [11]firstly discovered that $C$. pneumoniae infection might be an independent hazards for lung carcinoma in 1997 according to the relevant observation case-control research. Since then, the potential risk of $C$. pneumoniae and lung cancer has been vividly studied[12-14], but the results have been inconsistent. In order to comprehensively evaluate the association between $C$. pneumonia is infection and lung carcinoma, and to provide scientific basis for the etiology study, clinical treatment of lung cancer, we performed the meta-analysis from all eligible researches to explore the relationship between $C$. pneumoniae infection and lung carcinoma risk.

\section{Methods}

\section{Search strategy}

A systematic search was performed conducted on Pubmed, Embase, Ovid, Wanfang and China National Knowledge Infrastructure (CNKI) databases. The search terms were as follows: "Chlamydia pneumoniae”," "lung 
cancer" and their synonyms or similar words (from their inception to February, 2019). Searches were limited to English and Chinese literature and were first screened by two independent reviewers. Furthermore, reference lists of all included articles and related comments were searched manually to find other potentially eligible articles.

\section{Inclusion and exclusion criteria}

For inclusion, articles were selected on the basis of the following criteria: (1) Evaluating the relationship between C. pneumoniae infection and lung carcinoma risk; (2) study design was limited to prospective cohort studies or retrospective case-control studies; (3) clinical pathology confirmed lung cancer patients; (4) the control group was relative healthy people with no diagnosis of any cancer; (5) the $C$. pneumoniae infection rate can be extracted from the included individual studies.

\section{Assessment of Methodological Quality of Included Articles}

All articles met the inclusion criteria were estimated to evaluate the danger of bias for each outcome. The evaluation was conducted independently by two comments using the Cochrane Collaboration's risk of bias tool as depictive in the Cochrane Handbook for Systematic Reviews of Interventions (Higgins JPT, Green S. Cochrane handbook for systematic reviews of interventions, version 5.1.0. 2011, http://handbook.cochrane.org/). If there is any disagreement in the evaluation study, we will discuss it. The results of the assessment measure the following areas: random sequence generation, allocation concealment, blinding, incomplete outcome data addressed, free of selective outcome reporting, and other possible sources of bias. The consequences of the meta-analysis were comprehend as the results of the study on the risk of bias.

\section{Data extraction}

Data collection and analysis were carried out in accordance with the standard Cochrane protocol[15]. Two authors independently reviewed and extracted the following data from every study: study design, study year, participants number, the positivity or negativity for $C$. pneumoniae(lgA, IgG) antibody.

We attempted to find and exclude duplicate data from different studies. For multiple studies of repeated or overlapping data (by population, time, location, and results), we follow the PRISMA reporting guidelines when submitting manuscripts.

\section{Statistical analysis}

Meta-analysis were performed with the Cochrane Collaboration's Review Manager Software (RevMan, version 5.1.). Odds Ratio (OR) with $95 \% \mathrm{Cl}$ (confidence interval) was performed to evaluate the potential relationship between chronic $C$. pneumoniae infection and lung carcinoma risk. Heterogeneity was evaluated by I square 
test. Random effects model was used ifheterogeneity was significant $\left(I^{2}>50 \%\right)$. When heterogeneity was not detected or the heterogeneity was relatively small, fixed effects model was performed.

\section{Results}

\section{Literature Selection and Bias}

Totally of 65 potentially related researches and abstracts were identified (Fig 1). After removal of repeats ( $n=$ 21 ) and filtration of abstracts $(n=23), 21$ full-text researches were evaluated for eligibility. Eight studies were excluded for the following: abstract $(n=2)$, letter $(n=2)$, duplicated data $(n=3)$, study on Chlamydia pneumonia-antigen $(n=1)$. Thirteen publications $[11,16-27]$ were ultimately eligible for final meta-analysis. No more citations were found from the reference review.

The detail of the risk-of-bias evaluation of included researches was summarized in Fig. 2. All studies were evaluated as low risk according to the appropriate randomization sequence. However, many relative information in the studies wasn't available, such as allocation concealment and blinding of participants and personnel, blinding of outcome assessment. Nevertheless, the overall methodological quality was generally fair.

\section{Intervention Characteristics}

The included articles were printed between 1997 and 2013, involving 2553 lung cancer cases and 2460 controls. Controls were predominantly healthy people and matched for age, sex and/or smoking status. Of the 13 included articles[11,16-27], 6 were published in Chinese and 7 papers were published in English. For the study design, three articles were nest case-control and other 10 were case-control studies. Sample sizes ranged from 103 to 1264. The characteristics of the studies is presented in Table1.

\section{Relationship Between $C$. pneumoniae IgA Antibody and Lung Carcinoma}

Eleven studies reported the relationship between $C$. pneumoniae infection and lung carcinoma risk by using the serum IgA. Among them, significant heterogeneity was scanned $\left(I^{2}=91 \%\right.$; heterogeneity $P<0.00001 ;$ Fig. 3$)$. Random effect model was performed and the result showed that the $C$. pneumoniae infection significantly improved the risk of lung carcinoma $(\mathrm{OR}=3.19 ; 95 \% \mathrm{Cl}=1.96-5.19 ; \mathrm{p}<0.00001)$..

\section{Relationship Between C. pneumoniae IgG Antibody and Lung Carcinoma}

Ten studies reported the relationship between $C$. pneumoniae infection and lung carcinoma risk by using the serum IgG. Among them, significant heterogeneity was scanned $\left(I^{2}=88 \%\right.$; heterogeneity $P<0.00001 ;$ Fig. 4). Random effect model was performed and the result showed that the $C$. pneumoniae infection significantly improved the risk of lung carcinoma $(\mathrm{OR}=2.02 ; 95 \% \mathrm{Cl}=1.29-3.16 ; \mathrm{p}<0.00001)$. 


\section{Discussion}

Lung carcinoma is reported to be the most common cancer among women and men, representing huge social and economic burdens in both developing and developed countries[28]. However, the risk factors for its occurrence has not been fully understood. In recent years, studies have reported that the pulmonary inflammatory disease is significantly related to the risk of lung carcinoma. C. pneumonia, which is closely related to chronic lung inflammation and may act an significant part in progression of lung carcinoma [29]. Therefore, we performed the meta-analysis of all published articles to determine the relationship between $C$. pneumoniae infection and lung carcinoma risk. Our meta-analysis included 13 studies, including 2553 lung carcinoma cases and 2460 controls. Results showed that $C$. pneumoniae infection was significant related to the risk of lung carcinoma, with a 3.19-fold increased risk compared to a negative titre (95\% $\mathrm{Cl} 1.96-5.19)$ for lgA and 2.02-times (95\% Cl 1.29-3.16) for IgG.

The association between $C$. pneumoniae infection and lung carcinoma is reasonable in biology, but the mechanism is still not clear. There are three possible reasons for this mechanism.

Firstly, chronic inflammation played an important part in development of malignant transformation[11]. Medicaments that induce inflammation, such as infectious substances, can induce stretched-out stimulation, leading to cell death and increased mitotic activity. Subsequent cell division that happens during the repair of the damaged tissue possibly enhance the risk of cancer in the affected area[30]. For instance, several researches have linked chronic infection with Helicobacter pylori to an enhanced the risk of gastric adenocarcinoma[31,32]. Chumduri et al reported that Chlamydia trachomatis infection perturb host chromatin, DNA double-strand breaks (DSBs) repair, and cell-cycle regulation, thus promoting DNA double strand breaks in host cells, inducing genomic instability and leading to cancer[33]. C. pneumoniae may act a similar part in the occurrence and progress of lung carcinoma. C. pneumoniae promotes the delivery of inflammatory mediators, such as tumor necrosis factor, interleukin-1h, and interleukin-8 [34]. Chronic infection mediators, especially interleukin-8, may lead to genetic damage. Interleukin-8 also promotes the growth of human non-small cell lung carcinoma(NSCLC) by its angiogenic characteristics. In addition, $C$. pneumoniae may damage or even block apoptosis in infected cells via inducting interleukin-10 [35], leading to chronic infection and increasing the risk of vicious transformation of infected cells.

On the other hand, molecular simulation theory. Persistent $C$. pneumoniae infection could cause the release of endotoxin-like substance chlamydial heat shock protein-60 (CHSP- 60). CHSP- 60 is expressed throughout the life cycle of $C$. pneumoniae infection and may act a major part in the pathogenesis of lung carcinoma[36]. In addition, Mayer et al. also demonstrated that $C$. pneumoniae infection may cause the release of nitric oxide[37], the mutagenicity of nitric oxide and other metabolites has been confirmed elsewhere[38].

Last but not least, some studies have reported that $C$. pneumoniae infection promotes the liberation of inflammatory mediators, such as nuclear factor-kappa B (NF-KB), tumor necrosis factor-a (TNF-a), and interleukin-8[34], triggering the abnormal inflammatory response. Overexpression of inflammatory mediators and inadequate production of anti-inflammatory mediators can cause inflammatory reactions in the body, which in turn lead to overexpression of toll-like receptor (TLR) on the cell surface. However, the TLR signaling pathway may act a part in the carcinogenesis and progression of tumors. Bauer et al revealed that TLR4-mediated gene 
expression pathways, which can be used as prognostic marks for predicting lung cancer susceptibility in mice [39].

The present study has several limitations that ought be considered. Firstly, heterogeneity is a underlying conundrum when explanation all the studies of meta-analyses. Although we carefully searched the published articles, using explicit research inclusion criteria, strictly performed data collection and analysis, the significant heterogeneity between researches still existed. The existence of heterogeneity could arise from differences in the choose of controls, age distribution, prevalence rates and so on. Secondly, the inconsistency of the study population may lead to uncertainty in the research results.

\section{Conclusion}

In summary, the results of this meta-analysis demonstrate that the $C$. pneumoniae infection may increase the risk of lung carcinoma. Future prospective studies with extensive people are required to validate the connection of $C$. pneumoniae infection and lung carcinoma.

\section{Declarations}

\section{Acknowledgements}

The author thanked all the commentators, they reviewed and extracted the relevant data from every study.

\section{Funding}

No funding was received.

\section{Availability of data and materials}

PubMed, Embase, Embase, Ovid, Wanfang and China National Knowledge Infrastructure (CNKI) database

\section{Authors' contributions}

CXW, NXZ and LG conceived and designed this review article. CXW and NXZ reviewed and extracted the data from every study. CXW and LG carried out the meta-analysis with the Cochrane Collaboration's Review Manager Software (RevMan, version 5.1.). NXZ critically revised the article for important intellectual content. All authors have read and approved the final manuscript.

\section{Ethics approval and consent to participate}

Not applicable. 


\section{Patient consent for publication}

Not applicable

\section{Competing interests}

The authors declare that they have no competing interests.

\section{Reference}

1 Bray F, Ferlay J, Soerjomataram I, Siegel RL, Torre LA, Jemal A: Global cancer statistics 2018: GLOBOCAN estimates of incidence and mortality worldwide for 36 cancers in 185 countries. CA: a cancer journal for clinicians 2018;68:394-424.

2 Zhang X, Yang Q: Association between serum copper levels and lung cancer risk: A meta-analysis. The Journal of international medical research 2018:300060518798507.

3 Ou SH: Lung cancer in never-smokers. Does smoking history matter in the era of molecular diagnostics and targeted therapy? Journal of clinical pathology 2013;66:839-846.

4 Islami F, Torre LA, Jemal A: Global trends of lung cancer mortality and smoking prevalence. Translational lung cancer research 2015;4:327-338.

5 Liu C, Cui H, Gu D, Zhang M, Fang Y, Chen S, Tang M, Zhang B, Chen H: Genetic polymorphisms and lung cancer risk: Evidence from meta-analyses and genome-wide association studies. Lung cancer (Amsterdam, Netherlands) 2017;113:18-29.

6 Papadopoulos D, Papadoudis A, Kiagia M, Syrigos K: Nonpharmacologic Interventions for Improving Sleep Disturbances in Patients With Lung Cancer: A Systematic Review and Meta-analysis. Journal of pain and symptom management 2018;55:1364-1381.e1365.

7 Radouani F, El Yazouli L, Elyazghi Z, Hejaji H, Alami AA, Elmdaghri N: Chlamydia pneumoniae sero-prevalence in Moroccan patients with cardiovascular diseases. Infection, disease \& health 2018

8 Schmidt SM, Muller CE, Bruns R, Wiersbitzky SK: Bronchial Chlamydia pneumoniae infection, markers of allergic inflammation and lung function in children. Pediatric allergy and immunology : official publication of the European Society of Pediatric Allergy and Immunology 2001;12:257-265.

9 Burillo A, Bouza E: Chlamydophila pneumoniae. Infectious disease clinics of North America 2010;24:61-71.

10 Kuo CC, Jackson LA, Campbell LA, Grayston JT: Chlamydia pneumoniae (TWAR). Clinical microbiology reviews 1995;8:451-461.

11 Laurila AL, Anttila T, Läärä E, Bloigu A, Virtamo J, Albanes D, Leinonen M, Saikku P: Serological evidence of an association between Chlamydia pneumoniae infection and lung cancer. International journal of cancer 
12 Smith JS, Kumlin U, Nyberg F, Fortes C, Zaridze D, Ahrens W, Bruske-Hohlfeld I, Constantinescu V, Ting J, Benhamou S, Simonato L, Boman J, Gaborieau V, Boffetta P: Lack of association between serum antibodies of Chlamydia pneumoniae infection and the risk of lung cancer. International journal of cancer 2008;123:24692471.

13 Konstantopoulou S, Karachalios S, Mourikis A, Logothetis E, Strandzalis N, Demeridou S, Kontou-Castellanou C, Kouskouni E: Chronic Chlamydia pneumoniae infection and risk of lung cancer. Clin microbiol infect, Suppl 2003;9:203.

14 Aksaray S, Suzuk S, Guvener E, Unsal E, Urunal B, Aksaray F, Han S, Sakinci U: Association of Chlamydia pneumoniae seropositivity and lung cancer. Clin microbiol infect, Suppl 2004;10:661.

15 Furlan AD, Pennick V, Bombardier C, van Tulder M: 2009 updated method guidelines for systematic reviews in the Cochrane Back Review Group. Spine 2009;34:1929-1941.

16 Chaturvedi AK, Gaydos CA, Agreda P, Holden JP, Chatterjee N, Goedert JJ, Caporaso NE, Engels EA: Chlamydia pneumoniae infection and risk for lung cancer. Cancer epidemiology, biomarkers \& prevention : a publication of the American Association for Cancer Research, cosponsored by the American Society of Preventive Oncology 2010;19:1498-1505.

17 Fei H, Cailin: Association of Chlamydia pneumoniae infection with risk of lung cancer. Chinese Journal of Public Health 2014;30:70-73.

18 Jackson LA, Wang SP, Nazar-Stewart V, Grayston JT, Vaughan TL: Association of Chlamydia pneumoniae immunoglobulin A seropositivity and risk of lung cancer. Cancer epidemiology, biomarkers \& prevention : a publication of the American Association for Cancer Research, cosponsored by the American Society of Preventive Oncology 2000;9:1263-1266.

19 Kocazeybek B: Chronic Chlamydophila pneumoniae infection in lung cancer, a risk factor: A case-control study. Journal of Medical Microbiology 2003;52:721-726.

20 Koyi H, Branden E, Gnarpe J, Gnarpe H, Steen B: An association between chronic infection with Chlamydia pneumoniae and lung cancer. A prospective 2-year study. APMIS : acta pathologica, microbiologica, et immunologica Scandinavica 2001;109:572-580.

21 Littman AJ, White E, Jackson LA, Thornquist MD, Gaydos CA, Goodman GE, Vaughan TL: Chlamydia pneumoniae infection and risk of lung cancer. Cancer epidemiology, biomarkers \& prevention : a publication of the American Association for Cancer Research, cosponsored by the American Society of Preventive Oncology 2004;13:1624-1630.

22 Liu Z, Su M, Yu SC, Yin ZH, Zhou BS: Association of Chlamydia pneumoniae immunoglobulin G antibodies with the risk of lung cancer among non-smoking women in Liaoning, China. Thoracic cancer 2010;1:126-129.

23 Meichun Z, Qoing C, Chengping H, Tiesheng H: Chlamydia pneumoniae infection in patients with lung cancer and chronic obstructive pulmonary disease. China Journal of Modern Medicine 2004;14:31-34,40. 
24 Xiumei W: Investigation of chlamydia pneumoniae infection in respiratory inpatients. Chinese Community Doctors 2010;12:81.

25 Yanbin C, Yueduo T, Chunhua L, Jianan H, Jiayong M, Ling W, Rongmei Z: Association between chlamydia pneumoniae infection and lung cancer. Jiangsu Medical Journal 2005;31:306.

26 Yanbin C, Yueduo T, Chunhua L, Jianan H, Minrong Z: Serological study of an association between chronic Chlamydia pneumoniae infection and respiratory tract diseases in the elderly. Practical Geriatrics 2004;18:303304,307 .

27 Yuqing C, Liming L, Fengchao W, Peiying X, Anchao W, Fengzhen X: Study on Chlamydia pneumoniae infection in patients with Lung Cancer. Chinese journal of zoonoses 2001;17:46-49.

28 Minguet J, Smith KH, Bramlage P: Targeted therapies for treatment of non-small cell lung cancer-Recent advances and future perspectives. International journal of cancer 2016;138:2549-2561.

29 Qunxia C, Lin C: Association of Cpn infection with lung cancer: a meta-analysis of serological studies. Chinese Journal of Public Health 2015;31:1095-1099.

30 Preston-Martin S, Pike MC, Ross RK, Jones PA, Henderson BE: Increased cell division as a cause of human cancer. Cancer research 1990;50:7415-7421.

31 Bjorkholm B, Falk P, Engstrand L, Nyren O: Helicobacter pylori: resurrection of the cancer link. Journal of internal medicine 2003;253:102-119.

32 Sipponen P: Gastric cancer: pathogenesis, risks, and prevention. Journal of gastroenterology 2002;37 Suppl 13:39-44.

33 Chumduri C, Gurumurthy RK, Zadora PK, Mi Y, Meyer TF: Chlamydia infection promotes host DNA damage and proliferation but impairs the DNA damage response. Cell host \& microbe 2013;13:746-758.

34 Gaydos CA: Growth in vascular cells and cytokine production by Chlamydia pneumoniae. The Journal of infectious diseases 2000;181 Suppl 3:S473-478.

35 Geng Y, Shane RB, Berencsi K, Gonczol E, Zaki MH, Margolis DJ, Trinchieri G, Rook AH: Chlamydia pneumoniae inhibits apoptosis in human peripheral blood mononuclear cells through induction of IL-10. Journal of immunology (Baltimore, Md : 1950) 2000;164:5522-5529.

36 Biasucci LM, Liuzzo G, Ciervo A, Petrucca A, Piro M, Angiolillo DJ, Crea F, Cassone A, Maseri A: Antibody response to chlamydial heat shock protein 60 is strongly associated with acute coronary syndromes. Circulation 2003;107:3015-3017.

37 Mayer J, Woods ML, Vavrin Z, Hibbs JB, Jr.: Gamma interferon-induced nitric oxide production reduces Chlamydia trachomatis infectivity in McCoy cells. Infection and immunity 1993;61:491-497.

38 Arroyo PL, Hatch-Pigott V, Mower HF, Cooney RV: Mutagenicity of nitric oxide and its inhibition by antioxidants. Mutation research 1992;281:193-202. 
39 Bauer AK, Fostel J, Degraff LM, Rondini EA, Walker C, Grissom SF, Foley J, Kleeberger SR: Transcriptomic analysis of pathways regulated by toll-like receptor 4 in a murine model of chronic pulmonary inflammation and carcinogenesis. Molecular cancer 2009;8:107.

\section{Tables}

Table 1 Main characteristics of the studies included in the meta-analysis

\begin{tabular}{|c|c|c|c|c|c|c|c|c|}
\hline \multirow[t]{2}{*}{$\begin{array}{l}\text { Included } \\
\text { studies }\end{array}$} & \multirow[t]{2}{*}{\begin{tabular}{|l} 
studies \\
design
\end{tabular}} & \multirow[t]{2}{*}{$\begin{array}{l}\text { Sample } \\
\text { size }\end{array}$} & \multirow[t]{2}{*}{ Age, years } & \multirow[t]{2}{*}{ Sex(male/female) } & \multicolumn{2}{|c|}{ Case (positive/all) } & \multicolumn{2}{|c|}{$\begin{array}{l}\text { Control } \\
\text { (positive/all) }\end{array}$} \\
\hline & & & & & $\operatorname{Ig} \mathrm{A}$ & IgG & $\operatorname{Ig} \mathrm{A}$ & IgG \\
\hline Chen 2001 & $\begin{array}{l}\text { Case- } \\
\text { control }\end{array}$ & $80: 80$ & $58 \pm 17: 57 \pm 19$ & $64 / 16: 64 / 16$ & $69 / 80$ & & $57 / 80$ & \\
\hline Chen 2004 & $\begin{array}{l}\text { Case- } \\
\text { control }\end{array}$ & $50: 108$ & NA : $40.8 \pm 8.5$ & NA : $63 / 45$ & $28 / 50$ & & $22 / 108$ & \\
\hline Zhang 2004 & \begin{tabular}{|l|} 
Case- \\
control
\end{tabular} & $128: 70$ & $67.8: 52.3$ & 99/29:46/24 & & $3 / 128$ & & $1 / 70$ \\
\hline Chen 2005 & \begin{tabular}{|l|} 
Case- \\
control
\end{tabular} & $87: 108$ & $\begin{array}{l}50.9 \pm 11: \\
48.1 \pm 10.1 \\
\end{array}$ & $51 / 36: 63 / 45$ & $56 / 87$ & $62 / 87$ & $22 / 108$ & $51 / 108$ \\
\hline Wu 2010 & \begin{tabular}{|l|} 
Case- \\
control
\end{tabular} & $36: 67$ & NA & NA : $40 / 27$ & $26 / 36$ & & $6 / 67$ & \\
\hline He 2013 & \begin{tabular}{|l|} 
Case- \\
control
\end{tabular} & $185: 190$ & $\begin{array}{l}58.57 \pm 9.49: \\
57.96 \pm 9.28\end{array}$ & $133 / 52: 135 / 55$ & $49 / 185$ & $110 / 185$ & $13 / 190$ & $65 / 190$ \\
\hline $\begin{array}{l}\text { Laurila } \\
1997\end{array}$ & \begin{tabular}{|l|}
$\begin{array}{l}\text { Nest } \\
\text { case- } \\
\text { control }\end{array}$ \\
\end{tabular} & $230: 230$ & 60.3:60.3 & NA & $129 / 230$ & $225 / 230$ & $106 / 230$ & $219 / 230$ \\
\hline $\begin{array}{l}\text { Jackson } \\
2000\end{array}$ & \begin{tabular}{|l|} 
Case- \\
control \\
\end{tabular} & $143: 147$ & 59.8:59.4 & NA & $67 / 143$ & $114 / 143$ & $56 / 147$ & $118 / 147$ \\
\hline Koyi 2001 & \begin{tabular}{|l|} 
Case- \\
control
\end{tabular} & $198: 68$ & & 128/70: & $116 / 198$ & $88 / 198$ & $11 / 68$ & $13 / 68$ \\
\hline $\begin{array}{l}\text { Kocazeybek } \\
2003\end{array}$ & \begin{tabular}{|l|} 
case- \\
control
\end{tabular} & $123: 123$ & $55: 55: 00$ & 101/22:101/22 & $62 / 123$ & $98 / 123$ & $25 / 123$ & $62 / 123$ \\
\hline $\begin{array}{l}\text { Littman } \\
2004\end{array}$ & \begin{tabular}{|l|}
$\begin{array}{l}\text { Nest } \\
\text { case- } \\
\text { control }\end{array}$ \\
\end{tabular} & $508: 508$ & 59:59:00 & $254 / 254: 254 / 254$ & $281 / 508$ & $324 / 508$ & $261 / 508$ & $326 / 508$ \\
\hline $\begin{array}{l}\text { Chaturvedi } \\
2010\end{array}$ & \begin{tabular}{|l|} 
nest \\
case- \\
control
\end{tabular} & 593:671 & NA & 407/186:437/234 & $174 / 593$ & $293 / 593$ & $201 / 671$ & $356 / 671$ \\
\hline Liu 2010 & \begin{tabular}{|l|} 
case- \\
control
\end{tabular} & 192:90 & $54.6 \pm 10.4: 53.6 \pm 9.4$ & 0/192:0/90 & & $119 / 192$ & & $26 / 90$ \\
\hline
\end{tabular}

\section{Figures}


65 of records

identified through

database

searching

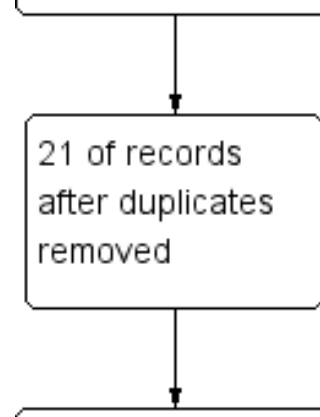

44 of records
screened

23 of records

excluded

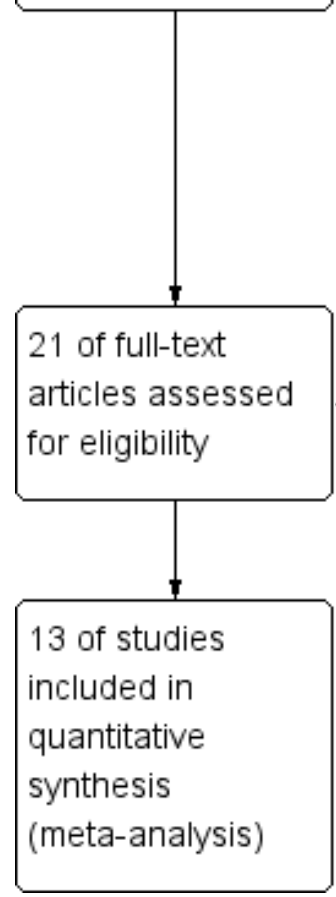

\section{Figure 1}

Flow chart showing results of the literature search and study inclusion. 


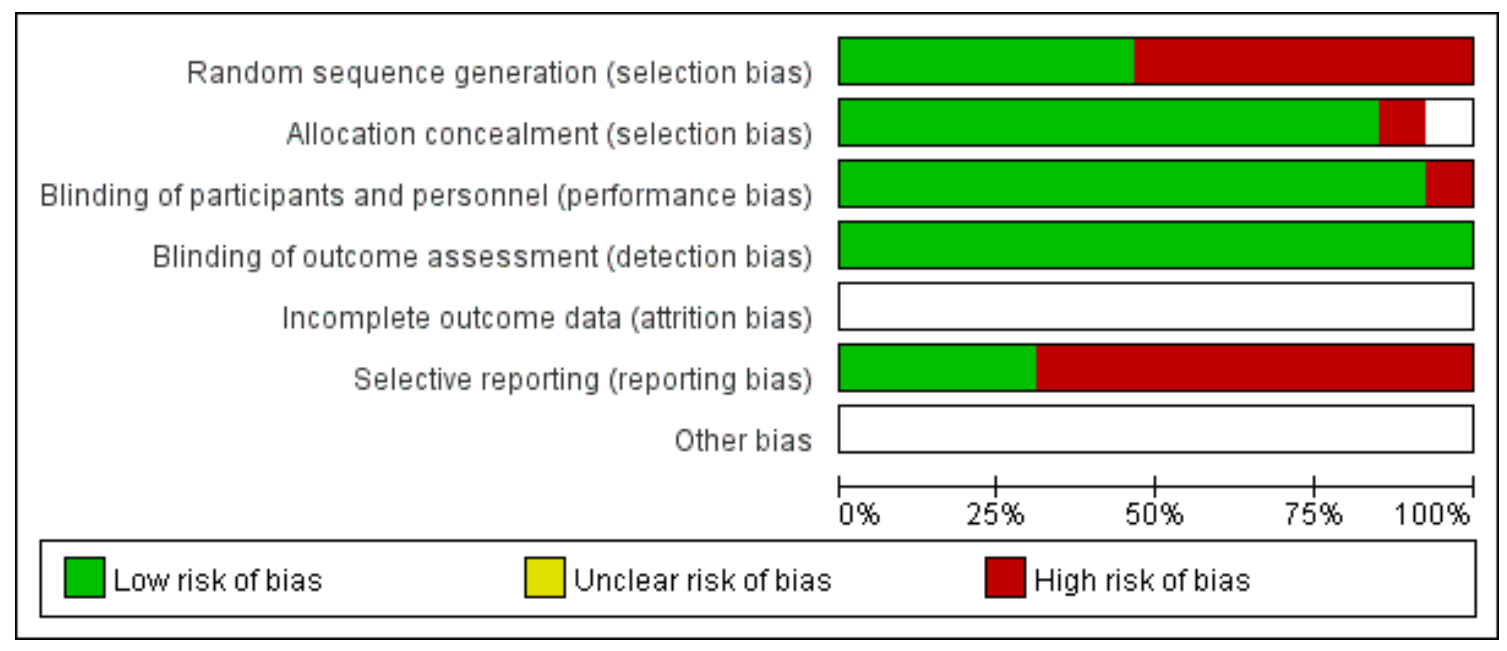

Figure 2

Risk of bias assessment in studies. Green indicates low risk of bias, yellow indicates medium risk of bias, and red indicates high risk of bias.

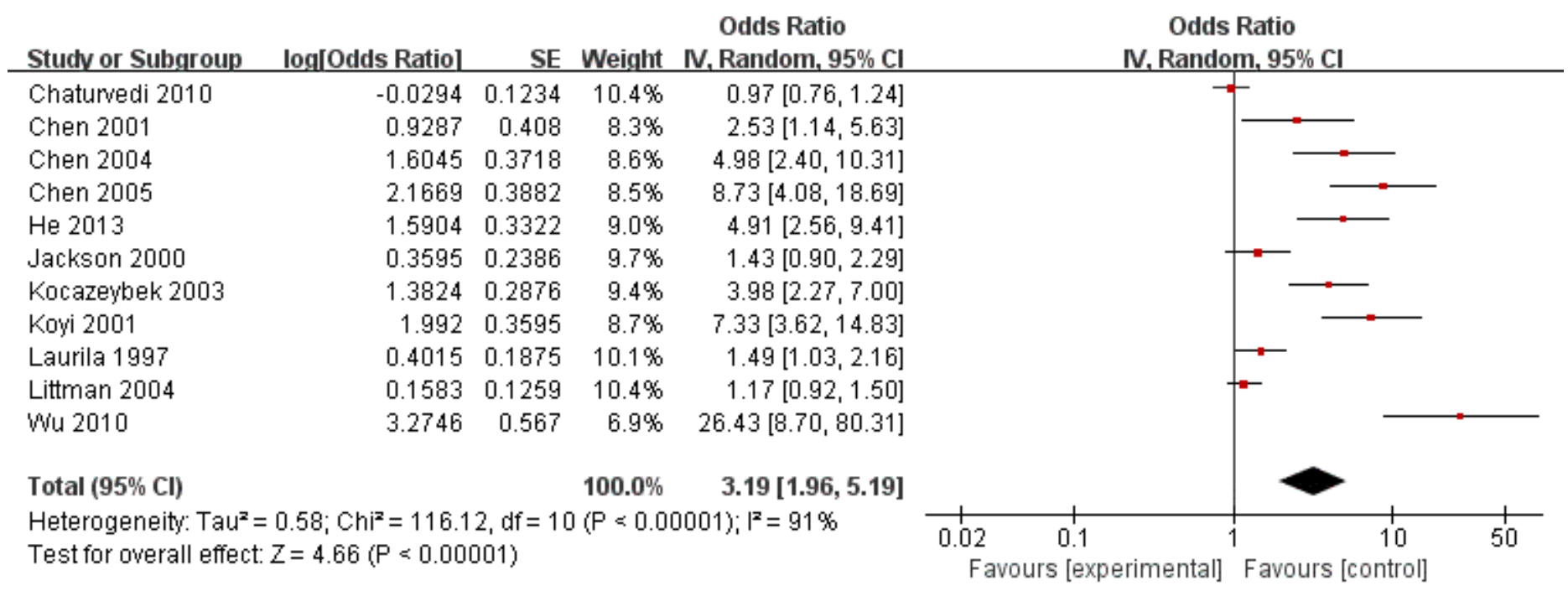

\section{Figure 3}

Forest plot for association between $\mathrm{C}$ pneumonia IgA infection and lung cancer risk.

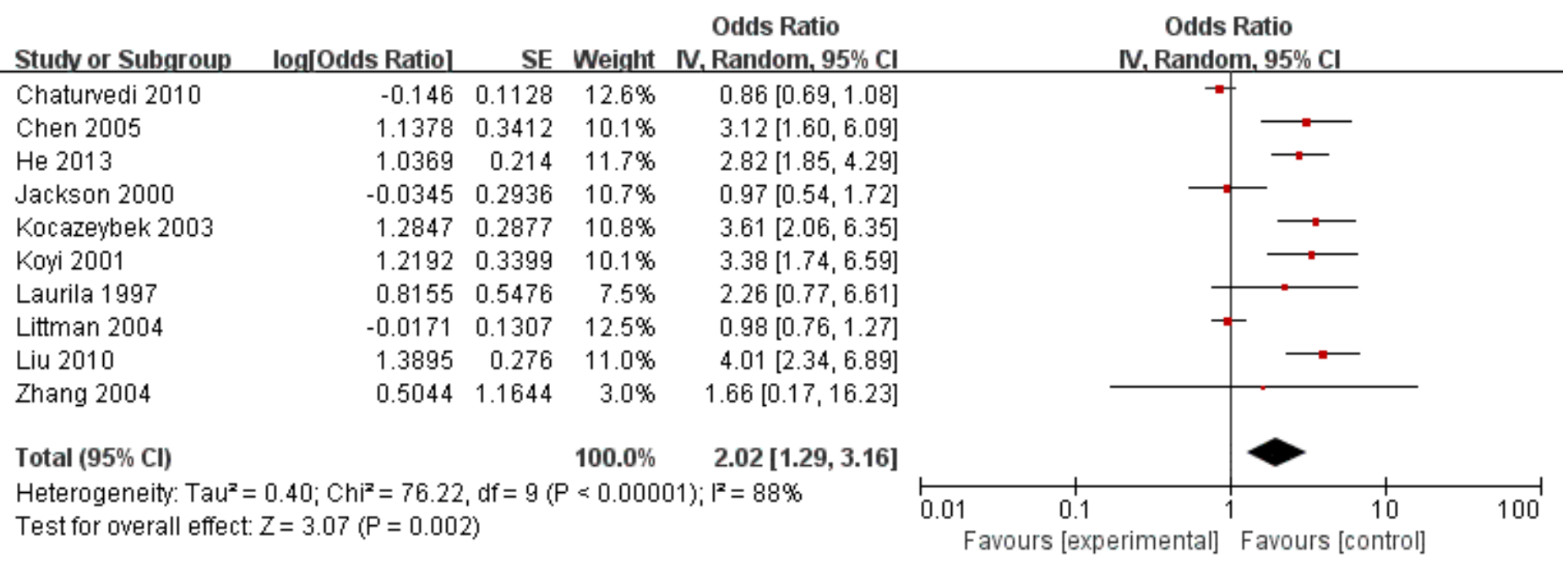


Figure 4

Forest plot for association between $\mathrm{C}$ pneumonia IgG infection and lung cancer risk. 